See Article page 1462.

\section{Commentary: The Vulcan mind MELD-XI}

\author{
Kenneth E. Mah, MD, MS, a,b and
}

David L. S. Morales, MD ${ }^{\mathrm{a}, \mathrm{b}, \mathrm{c}}$

Composite risk scores are valuable insofar as they enable a summative risk assessment by amalgamating multiple variables into one metric. They are commonly employed when a single variable does not confer sufficient risk itself to impact outcomes. Ascertaining the clinical relevance of a composite risk score and if it is actionable is often challenging. In contrast, although more elusive, individual risk factors with delineated relationships to outcomes are more facile to quantify, comprehend, and alter.

Composite risk scores assist in ascertaining risk but often do not provide insight into how to modulate this risk. Thus, clinicians may still find value in understanding which patients are high versus low risk, but individual patients may not derive value from composite scores as many scores are not used to change clinical trajectory. Composite risk scores include the Model for End-Stage Liver Disease, Model for End-Stage Liver Disease eXcluding INR (MELD-XI), and Pediatric End-Stage Liver Disease. ${ }^{1-5}$ Analogous metrics exist in athletics, such as basketball. The player efficiency rating is a composite score quantifying efficiency and gave rise to win shares, points per possession, and real plus-minus. ${ }^{6-9}$ Efficiency ratings are actionable because players attempt to change to become more efficient. However, composite risk scores are less actionable. Composite risk forecasts a patient's risk level but does not identify a clear mechanism to decrease that risk.

Amdani and colleagues ${ }^{10}$ demonstrate the MELD-XI score, a composite risk score combining renal and hepatic

\footnotetext{
From the ${ }^{\mathrm{a}}$ Department of Pediatrics, University of Cincinnati College of Medicine; and ${ }^{\mathrm{b}}$ The Heart Institute, Division of Cardiology, and ${ }^{\mathrm{c}}$ Division of Cardiothoracic Surgery, Cincinnati Children's Hospital Medical Center, Cincinnati, Ohio. Disclosures: The authors reported no conflicts of interest.

The Journal policy requires editors and reviewers to disclose conflicts of interest and to decline handling or reviewing manuscripts for which they may have a conflict of interest. The editors and reviewers of this article have no conflicts of interest.

Received for publication March 15, 2021; revisions received March 15, 2021; accepted for publication March 16, 2021; available ahead of print March 18, 2021.

Address for reprints: Kenneth E. Mah, MD, MS, The Heart Institute, Cincinnati Children's Hospital Medical Center, 3333 Burnet Ave, MLC 2003, Cincinnati, OH 45229 (E-mail: Kenneth.Mah@cchmc.org).

J Thorac Cardiovasc Surg 2022;163:1477-8

$0022-5223 / \$ 36.00$

Copyright (c) 2021 by The American Association for Thoracic Surgery

https://doi.org/10.1016/j.jtcvs.2021.03.052
}

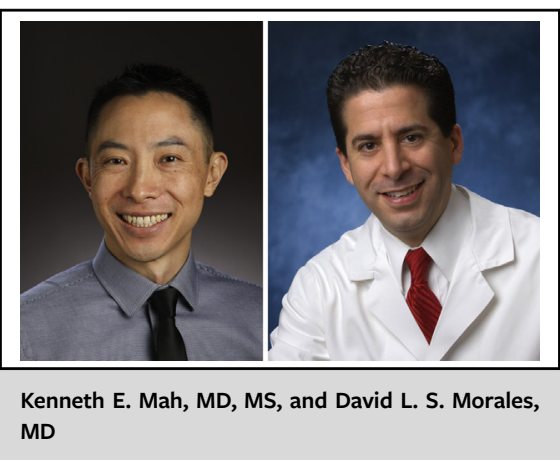

CENTRAL MESSAGE

Composite scores can ascertain patients' risk levels and have relationships with outcomes. However, clinical relevance may be limited due to not producing data actionable to enable risk modification.

function, has a relationship with outcomes after heart transplantation in patients with Fontan circulation. However, investigation is warranted to translate this score into one actionable by the clinician and valuable to the patient. For example, timing of the MELD-XI score calculation postFontan and appropriate clinician response remain unclear. Does MELD-XI have utility as a clinical target before listing? What is the relative contribution of renal versus hepatic function to the overall score and how should efforts be correspondingly prioritized to decrease risk? Once a high score is achieved, should transplantation listing or endeavors to decrease risk ensue? The approach likely should not be to avoid listing high-risk patients for transplantation, but this may be an unintended consequence at risk-adverse institutions.

Amdani and colleagues accentuate the need for studies to determine the relationship of outcomes and ventricular assist device (VAD) implantation in patients with high MELD-XI scores at transplantation listing with subsequent decrease to low MELD-XI scores at transplantation. If VADs "rescue" patients with high MELD-XI scores by reliably reducing risk and improving outcomes, MELD-XI may merit inclusion as VAD candidacy criteria. This would further raise the question of if and how MELD-XI scores should be acted on before listing.

Composite scores conveying patient risk increase clinician awareness. However, a composite score's utility is 
limited if it is not actionable. In Star Trek, Spock performs telepathy, the Vulcan mind meld, to exchange thoughts and understanding. The mind meld allows Spock to gain meaning from limited information. Similarly, composite risk scores provide limited data, and advances are essential, so obtaining actionable information to decrease a patient's risk does not require the Vulcan mind MELD-XI.

\section{References}

1. Kamath PS, Wiesner RH, Malinchoc M, Kremers W, Therneau TM, Kosberg CL, et al. A model to predict survival in patients with end-stage liver disease. Hepatology. 2001;33:464-70.

2. Heuman DM, Mihas AA, Habib A, Gilles HS, Stravitz RT, Sanyal AJ, et al. MELD-XI: a rational approach to "sickest first" liver transplantation in cirrhotic patients requiring anticoagulant therapy. Liver Transpl. 2007;13:30-7.

3. McDiarmid SV, Anand R, Lindblad AS. Development of a pediatric end-stage liver disease score to predict poor outcome in children awaiting liver transplantation. Transplantation. 2002;74:173-81.
4. Wiesner RH, McDiarmid SV, Kamath PS, Edwards EB, Malinchoc M, Kremers WK, et al. MELD and PELD: application of survival models to liver allocation. Liver Transpl. 2001;7:567-80.

5. Freeman RB Jr, Wiesner RH, Harper A, McDiarmid SV, Lake J, Edwards E, et al. The new liver allocation system: moving toward evidence-based transplantation policy. Liver Transpl. 2002;8:851-8.

6. Hollinger J. What is PER? ESPN.com. Available at: https://www.espn.com/nba/ columns/story? columnist $=$ hollinger_john\&id $=2850240$. Accessed March 14, 2021.

7. Kubatko J. NBA Win shares. Basketball Reference. Available at: https://www. basketball-reference.com/about/ws.html. Accessed March 14, 2021.

8. Points Per Possession. nba.com. Available at: https://www.nba.com/resources/ static/team/v2/thunder/statlab-en-october-1819-update.pdf. Accessed March 14, 2021.

9. Ilardi S. The next big thing: real plus-mins. Available at: https://abcnews.go.com/ Sports/big-thing-real-minus/story?id=23226009 ABC News via espn.com. Accessed March 14, 2021.

10. Amdani S, Simpson KE, Thrush P, Shih R, Simmonds J, Knecht K, et al. Hepatorenal dysfunction assessment with the Model for End-Stage Liver Disease eXcluding INR score predicts worse survival after heart transplant in pediatric Fontan patients. J Thorac Cardiovasc Surg. 2022;163:1462-73.e12. 